\title{
Determinants of satisfaction with health care provider interactions at health centres in central Ethiopia: a cross sectional study
}

\author{
Zewdie Birhanu', Tsion Assefa', Mirkuzie Woldie ${ }^{2 *}$, Sudhakar Morankar ${ }^{1}$
}

\begin{abstract}
Background: In primary health care, provider-patient interaction is fundamental platform and critically affects service delivery. Nevertheless, it is often ignored in medical research and practice and it is infrequently subjected to scientific inquiry, particularly in Ethiopia. This study aimed to assess patient satisfaction with health care provider interactions and its influencing factors among out-patients at health centers in West Shoa, Central Ethiopia.

Methods: A cross sectional facility based study was conducted on 768 out-patients of six health centers in West Shoa Zone, Central Ethiopia. The total sample size was allocated to each of the six health centers based on patient flow during the ten days prior to the start of data collection. Pre-tested instruments were used for data collection and the data were analyzed using SPSS version 16.0 statistical software. Factor score was computed for the items identified to represent the satisfaction scale by varimax rotation method. Using this regression factor score, multivariate linear regression analysis was performed and the effect of independent variables on the regression factor score was quantified.
\end{abstract}

Results: Seventy three percent of the respondents perceived that provider's empathy was good and 35\% complained that providers were not technically competent enough. In addition, $82 \%$ of the respondents rated non-verbal communication by the providers to be good, very good or excellent on a five-point ordinal scale. Regardless of the process, only $34.1 \%$ of the patients implied that the consultations made a difference in understanding their illness and coping with it. Generally speaking, $62.6 \%$ of the patients reported that they have been satisfied with their visit. Perceived empathy, perceived technical competency, non-verbal communication, patient enablement, being told the name of once illness, type and frequency of visit, knowing the providers and educational status were main independent predictors of patient satisfaction in this study. Furthermore, very good empathy (Beta $=-4.323)$, fair non-verbal communication (Beta $=-0.188)$, fewer expectations met $($ Beta $=-0.169)$ and disagreement to technical competency (Beta $=-0.156$ ) had greater negative influence on patient satisfaction. On the other hand, excellent non-verbal communication (Beta $=0.114$ ) and being told the name of once illness $(0.109)$ had pronounced positive influence on patient satisfaction.

Conclusion: The present study showed that interpersonal processes including perceived empathy, perceived technical competency, non-verbal communication and patient enablement significantly influence patient satisfaction. Therefore, health care providers should work towards improving the communication skill of their professionals along with having technically competent workers which could possibly affect the perception of the patient about all of the variables identified as independent predictors of patient satisfaction in this study.

\footnotetext{
* Correspondence: mirkuzie@yahoo.com

${ }^{2}$ Jimma University, Public Health Faculty, Department of Health Services

Management, Jimma, Ethiopia
}

\section{) Biomed Central}

(c) 2010 Birhanu et al; licensee BioMed Central Ltd. This is an Open Access article distributed under the terms of the Creative Commons Attribution License (http://creativecommons.org/licenses/by/2.0), which permits unrestricted use, distribution, and reproduction in any medium, provided the original work is properly cited. 


\section{Background}

A wealth of literature reflects the progress made in developing tools to monitor and improve the quality of health care. In developing countries, however, interest in the issue has been surprisingly low until recently. This is so, in spite of overwhelming published and anecdotal evidence of low quality of care in these countries [1].

In Ethiopia, health services are limited and of poor quality [2] and the country has extremely poor health status relative to other low-income countries. To solve this problem, the government has focused on improving the organization and quality of health services delivered to the population. This is because improving the poor quality of care delivered to patients is one of the strategies to reduce the burden of communicable diseases and plays a significant role in attaining the Millennium Development Goals (MDGs). This intention of the government was reflected in the 1993 health policy and the health sector development plans of the country. In such efforts towards improving quality of health care, patient satisfaction is integral component of health services provided to the population [3-11].

It is generally agreed that satisfaction data play significant role in the strategy and tactics health care providers use in delivering services for clients. In addition, measurement of patient satisfaction is increasingly playing important role in the growing push towards accountability among health care providers. It is also viewed as an established indicator of quality of care despite it was overshadowed by measures of organizational aspects in the quality of health care equation $[12,13]$.

Empathy, which is a core component of consultation, is often seen as crucial to the effective achievement of patient satisfaction in that it encapsulates sensitivity to both the informational and emotional aspects of communication [14]. Even though, many standards and codes of practice refer to the importance of empathy in medical consultation, it is an aspect of practice which is too often overlooked $[15,16]$. Non-verbal cues and languages convey information which words alone often do not. Providers who appear fully attentive, avoid distractions, smile, and sit on the same level as the patient all convey an important message of caring, listening, and empathy [2]. Besides, studies have documented that patient enablement also plays a significant role in patients' overall satisfaction $[17,18]$. It is also clear from the literature that although system aspects such as cost, access, availability and waiting time are related to patient satisfaction, they have always been identified as being less important than the human aspect of medical care. However, system factors asymmetrically guzzle much of the research topics regardless of their little contribution $[4,5]$. This is particularly true in the case of developing countries such as Ethiopia where much of the scientific inquiries in the areas of patient satisfaction exclusively focus on organizational aspects [18-20].

Furthermore, established evidences depicted that even though technical aspect of care has its impact on satisfaction, it is through interpersonal communication that the technology of western world reaches the patients and curing occurs. In addition, it is recognized more than ever that the quality of health care for the $21^{\text {st }}$ century is built on the premise that optimal health care can best be achieved in the context of long term relationship between providers and patients $[1,6]$. However, the issue of patient-provider interaction and its effect on the quality of care rendered at health care facilities is often ignored in medical researches and rarely subjected to scientific inquiry. Therefore, this study aimed to assess patient satisfaction with health care provider interactions and its influencing factors among out-patients of six health centres in West Shoa, Central Ethiopia. Hence, the research question of this study was: "what are the major determinants of patient satisfaction with their health care provider interaction in resource poor settings such as public health centres in Central Ethiopia?"

\section{Methods}

\section{Study area}

A cross sectional study was conducted from $29^{\text {th }}$ December $-21^{\text {st }}$ January, 2009 in West Shoa, Central Ethiopia. West Shoa is one of the 17 zones of the Oromia Regional State in Ethiopia and it comprises 21 districts. The zone has an estimated total population of 2,072, 485 of whom 1,037,159 are females.

All the health centres included in the study are government run facilities. The composition of health professionals in these facilities includes health officers, nurses, pharmacy technicians, laboratory technicians and environmental health technicians. However, Shortage of staff in the health system of Ethiopia has always been critical. For instance, health worker to population ratios are 3 to 4 times lower than even the East African standards. Hence, all the public health facilities included in this study function in this context which has clear implication on the quality of care delivered to their clients [2].

\section{Participants}

The study population was included patients who visited the adult medical out-patient departments (OPDs) at six health centers in West Shoa during the study period. A patient was included in the study if he/she is 15 years of age or older. The sample size was calculated assuming p, proportion of patients satisfied with provider 
interaction, to be $50 \%$. This has been preferred for the sample size determination due to lack of similar studies in Ethiopia. Other assumptions made during the sample size calculation were $5 \%$ marginal error (d) and confidence interval of $95 \%$. Based on these assumptions, the sample size was calculated as follows:

$$
n=\frac{z_{1-\alpha / 2}^{2} p(1-p)}{d^{2}}
$$

This yields a sample size of 384 . However, this was multiplied by a factor of 2 to correct the design effect of cluster sampling and the final sample size was $\mathbf{7 6 8}$.

\section{Sampling technique}

In West Shoa, there are twenty government run health centers. Of these eighteen health centers are located in rural districts while the remaining two belong to urban districts. In this study, one urban and five rural health centers were randomly selected to be included in the study. The total sample size was proportionally allocated to the six health centers based on the number of outpatients 15 years or older served at the adult medical OPDs during the ten days prior to the start of data collection. Finally, consecutive patients who full fill the inclusion criterion (age 15 years or older) were included in the study until the allocated size was obtained in each of the six health centers.

\section{Measurements}

The following instruments were adapted from similar studies:

\section{Consultation and Relational Empathy (CARE)}

The Consultation and Relational Empathy tool measures the patient's perception of the provider's empathy during the clinical encounter. Within the CARE tool patients were asked 10 questions to rate different aspects of empathy. Each question was scored on an ordinal scale from 'poor' to 'excellent. All ten items taken together yield a maximum score of 50 and a minimum of 10. Higher score on each item indicates higher level of empathy $[21,22]$. These 10 items were based on the following questions: Thinking about your today's visit, how was your provider at making you feel at ease, letting you tell your story, really listening, being interested in you as a whole person, fully understanding your concerns, being caring and compassionate, being positive, explaining things clearly, helping you to take control, and involving you in decision about treatment plan. The reliability coefficient (Cronbach's alpha) of the empathy scale was 0.964 indicating that the scale was internally consistent. To examine the underlying factors (components) of the empathy scale, an exploratory factor analysis was conducted and produced one meaningful factor with eigenvalue greater than one. This factor accounted for $75.5 \%$ of the total variance and thus the remaining items of the empathy scale were discarded during the linear regression analysis. Based on the contents of this scale and the magnitude of the eigenvalue the item used during this analysis was "making clients to feel at ease".

\section{Patient Enablement Instrument (PEI)}

In the PEI patients were asked to rate six questions whether, as a result of their most recent visit, they felt to be able to cope with life, understand their illness, cope with their illness, keep healthy, confident about their health, and help themselves. All items were stated positively, each capturing responses via an ordinal scale. The scoring system was same or less $=0$, better or more $=1$ and much better or much more $=2$. Taken together, the six items yield a score range of 0-12 [21]. The scale was reliable with Cronbach's alpha of 0.897 . The items of the scale were subjected to factor analysis to identify the underlying components of the PEI. Only one factor with eigenvalue greater than one was produced. This factor accounted for $68.6 \%$ of the total variance. Therefore, the item of "able to cope with life" was considered to be a core ingredient of this scale and was used in subsequent analysis.

\section{Perceived technical competency}

Perceived technical competency of the provider is the subjective judgment of the patients about the professional skills and abilities of the health care provider to detect and manage their problem. It was measured by 8 items. Each item was scored on a five-point Likert scale ranging from strongly disagree (1) to strongly agree (5) which yields a score range of 8-40. The scale has high internal consistency (Cronbach's $\alpha=0.910$ ). The items cover physical examination, procedural steps to arrive at what is wrong, experience of the provider, etc. The items of the scale were subjected to factor analysis to look into the underlying components. Accordingly, one component with eigenvalue greater than one was identified and it accounts for $72.6 \%$ of the overall variance. This item was the one considering the conduct of "thorough physical examination by the provider". This was considered as the central constituent of perceived technical competency and the remaining items with eigenvalues less than one were discarded.

\section{Perceived non-verbal communication of the provider}

Non-verbal communication involves a range of communication activities of the providers that do not have linguistic contents. Perception of patients about the health care provider's non-verbal communication was measured by five items on a five-point Likert scale ranging from poor (1) to excellent (5). The items cover different aspects of non-verbal communication including making eye contact, forward 
leaning, open posture, facial expression, head nodding, hand gesture, emotional expressive and concerned voice tone. Reliability check showed that the scale has high internal consistency (Cronbach's $\alpha=0.935$ ). During factor analysis the scale was reduced to one item ("making eye contact") with eigenvalue of greater than one. This item explained $69.0 \%$ of the overall variance.

\section{Actual consultation length}

is the amount of time the patients spend with the health care provider in the consultation room. The consultation duration was recorded by the data collectors who measured the minutes elapsed between entry to and exit from the examination room.

\section{Information sharing about illness}

Five items with yes/no response were used to measure the extent to which relevant information was given to patients in relation to their illness. These items checked whether the patients were told the name and cause of their illness, to return if illness gets worse and how to prevent reoccurrence.

\section{Patient satisfaction}

Patient satisfaction with the latest visit was assessed using five items on a five-point Likert scale ranging from strongly disagree (1) to strongly agree (5). This scale was found to have high internal consistency (Cronbach's $\alpha=0.887$ ). The items in this scale include: "I am totally satisfied with the visit", "Something about my consultation is better", "I am not completely satisfied with my visit", "I would come back to this provider" and "I would send my friends or relatives to this provider". However, when factor analysis was computed, only one factor with eigenvalue greater than one was identified. This item ("I am totally satisfied with the visit") explained $69.6 \%$ of the overall variance and was used during further analysis.

Finally, all of these tools were translated into Afan Oromo (the local language) and back translated into English to check its consistency by different persons and the one in Afan Oromo was pre-tested on 5\% of the sample size taken from a similar population before the start of the actual data collection. Data were collected by trained individuals who were not health professionals.

\section{Statistical analysis}

The data were analyzed using SPSS statistical software version 16.0. The mean score of the scales was computed for patient enablement, perceived empathy, technical competency and non-communication. Each scale was subjected to factor analysis to investigate the underlying components and to reduce the number of items based on eigenvalue. Factors with eigenvalue less than one were discarded and only those with eigenvalue greater than one were considered in subsequent analysis. Factor score was computed for the item identified to represent the satisfaction scale by varimax rotation method. Using this regression factor score, multivariate linear regression analysis was performed and the effect of independent variables on the regression factor score of the dependent variable was quantified. In the first model, the effects of sociodemographic variables were assessed while in the second model the effects of institutional variables were considered. In the third model, variables related to interpersonal interaction were included. Finally, explanatory variables which had statistically significant association with the dependent variable $(\mathrm{P}<0.05)$ were entered to the final regression model.

\section{Ethical consideration}

The ethical issues of this study were reviewed and approved by the Ethical Committee of Jimma University. During the study, verbal informed consent was sought from all the respondents before the start of each interview.

\section{Results}

\section{Socio-demographic characteristics of the respondents}

Seven hundred sixty eight patients aged 15 years or older were interviewed yielding a response rate of $100 \%$. Four hundred one $(52.2 \%)$ of the interviewed patients were females. The mean age of the patients was $29.5 \pm$ 10.6 years. More than six in ten $(62.2 \%)$ of the respondents reside in the rural area. Four hundred twenty six $(55.5 \%)$ of the respondents were married while 296 (38.5\%) were single. Concerning educational status, 240 (31.3\%) of the respondents cannot read and write and $147(19.1 \%)$ of them have attended primary education (grade 1-6). Occupationally, 286 (37.3\%) of the respondents were farmers.

\section{Socio-demographic predictors of patient satisfaction}

The relationship between socio-demographic variables and satisfaction factor score is quantified in table 1 below. Socio-demographic variables were found to explain only $3.9 \%$ of the variability in the satisfaction factor score. Accordingly, marital status, residence, educational status and occupational status appeared to be statistically associated with satisfaction factor score. The satisfaction score for single respondents was decreased by an average of 0.314 (95\%CI: -0.517 to -0.112) as compared to their married counterparts. Urban residents had 0.261 unit greater satisfaction score when compared to those from the rural area (95\%CI: 0.090 to 0.431 ).

\section{Institutional aspects and pattern of visit}

In this survey the mean time taken by the respondents to reach the health centers, regardless of the means, was 
Table 1 Socio-demographic determinants of patient satisfaction with health care provider interaction at public health centres, central Ethiopia, January 2009

\begin{tabular}{|c|c|c|c|c|}
\hline Socio-demographic Variables & No. (\%) & p-value & Unstandardized B coefficient & $95 \% \mathrm{Cl}$ for $\mathrm{B}$ \\
\hline \multicolumn{5}{|l|}{ Sex } \\
\hline Male & $36747.8)$ & .002 & -.314 & $(-.517,-.112)$ \\
\hline Female* & $40152.2)$ & & & \\
\hline Age & & .427 & -.004 & $(-.013, .005)$ \\
\hline \multicolumn{5}{|l|}{ Residence } \\
\hline Urban & $290(37.8)$ & .003 & .261 & $(.090, .431)$ \\
\hline Rural* $^{*}$ & $478(62.2)$ & & & \\
\hline \multicolumn{5}{|l|}{ Ethnicity } \\
\hline Oromo* & $693(90.3)$ & & & \\
\hline Ahmara & $57(7.4)$ & .527 & -.089 & $(-.366, .187)$ \\
\hline Others & $18(2.3)$ & .155 & -.352 & $(-.837, .133)$ \\
\hline \multicolumn{5}{|l|}{ Religion } \\
\hline Orthodox* & $429(55.9)$ & & & \\
\hline Protestant & $300(40.1)$ & .162 & -.105 & $(-.253, .043)$ \\
\hline Others & $39(5.0)$ & .919 & .018 & $(-.328, .364)$ \\
\hline \multicolumn{5}{|l|}{ Marital status } \\
\hline Single & $296(38.5)$ & .002 & -.314 & $(-.517,-.112)$ \\
\hline Married* & $426(55.5)$ & & & \\
\hline Divorced & $24(3.1)$ & .233 & -.264 & $(-.698, .170)$ \\
\hline Widowed & $22(2.9)$ & .626 & -.108 & $(-.545, .328)$ \\
\hline \multicolumn{5}{|l|}{ Educational status } \\
\hline Cannot read and write* & $240(31.3)$ & & & \\
\hline Can read and write & $123(16.0)$ & .504 & .077 & $(-.149, .303)$ \\
\hline Grade 1-6 & $147(19.1)$ & .175 & .155 & $(-.069, .380)$ \\
\hline Grade 7-12 & $207(27.0)$ & .023 & .282 & $(.038, .525)$ \\
\hline Diploma and above & $51(6.6)$ & .233 & .271 & $(-.175, .717)$ \\
\hline \multicolumn{5}{|l|}{ Occupational status } \\
\hline Farmer* & $286(37.3)$ & & & \\
\hline House wife & $158(20.6)$ & .042 & .227 & $(.008, .446)$ \\
\hline Student & $153(19.9)$ & .389 & .126 & $(-.162, .414)$ \\
\hline Government employment & $67(8.7)$ & .923 & .019 & $(-.375, .414)$ \\
\hline Merchant & $57(7.4)$ & .387 & -.141 & $(-.461, .179)$ \\
\hline Others & $47(6.1)$ & .987 & .003 & $(-.325, .330)$ \\
\hline
\end{tabular}

*References category (categories with highest frequency taken as reference categories)

82.4 minutes. Of the total respondents, 683 (88.9\%) were new patients while the remaining were repeat visitors. More than nine in ten $(96.2 \%)$ of the patients reported that they were interviewed in the language they understand. More than half (53.4\%) of the patients reported that they were seen by a male health care provider while 496 (64.6\%) of the respondents didn't previously know the health care provider who treated them. One hundred seventy six $(22.9 \%)$ of the respondents claimed that their privacy was not respected during consultation. Moreover, 153 (19.9\%) of the respondents felt that the consultation rooms did not provide adequate privacy. It was also found that $188(24.5 \%)$ of the respondents did not tell all of their private issues related to their health condition to the health care provider. However, 747
(97.3\%) and $676(88.0 \%)$ of the respondents felt that the waiting areas and seats were comfortable, respectively.

\section{Institutional aspects and pattern of visit as predictors of patient satisfaction}

Variables related to institutional aspects were entered into the second model and their relative effect and importance is presented in table 2. This model explained $15.4 \%$ of the variation in satisfaction among patients. Knowing the provider, frequency of visit, privacy of the room, feeling of privacy during consultation and telling one's own private issues had statistically significant association with patient satisfaction. Patients who knew the health care provider very well had an average increase of 0.499 unit in their satisfaction with 
Table 2 Institutional aspects and patient satisfaction with health care provider interaction at public health centres, central Ethiopia, January 2009

\begin{tabular}{|c|c|c|c|c|}
\hline Institutional Variables & No. (\%) & $\mathrm{p}$-value & Unstandardized B coefficient & $95 \% \mathrm{Cl}$ for $\mathrm{B}$ \\
\hline \multicolumn{5}{|l|}{ Sex of provider } \\
\hline Male* & $410(53.4)$ & & & \\
\hline Female & $358(46.6)$ & .786 & -.019 & $(-.158, .120)$ \\
\hline \multicolumn{5}{|c|}{ Knowing Health care provider } \\
\hline Know very well & $35(4.6)$ & .008 & .499 & $(.129, .870)$ \\
\hline Know well & $57(7.4)$ & .001 & .488 & $(.205, .772)$ \\
\hline Know little bit & $180(23.4)$ & .083 & .171 & $(-.022, .363)$ \\
\hline Don't know at all* & $496(64.6)$ & & & \\
\hline \multicolumn{5}{|c|}{ Frequency of visit in 12 months } \\
\hline Once $^{*}$ & $563(73.3)$ & & & \\
\hline Twice & $165(21.5)$ & .045 & -.229 & $(-.454,-.005)$ \\
\hline Three times & $29(3.8)$ & .583 & .102 & $(-.262, .466)$ \\
\hline$\geq 4$ times & $11(1.4)$ & .093 & -.518 & $(-1.123, .086)$ \\
\hline \multicolumn{5}{|l|}{ Type of visit } \\
\hline $\mathrm{New}^{*}$ & $683(89.9)$ & & & \\
\hline Follow up & $85(11.1)$ & .038 & .274 & $(.015, .532)$ \\
\hline \multicolumn{5}{|l|}{ Involvement of other } \\
\hline Yes & $198(25.8)$ & .855 & .014 & $(-.138, .167)$ \\
\hline $\mathrm{No}^{*}$ & $570(74.2)$ & & & \\
\hline \multicolumn{5}{|l|}{ Told your private issues } \\
\hline Yes* $^{*}$ & $580(75.5)$ & & & \\
\hline No & $188(24.5)$ & .000 & -.598 & $(-.761,-.435)$ \\
\hline \multicolumn{5}{|c|}{ Privacy during consultation } \\
\hline Yes* $^{*}$ & $592(77.1)$ & & & \\
\hline No & $176(22.9)$ & .000 & -.400 & $(-.570,-.230)$ \\
\hline \multicolumn{5}{|l|}{ Room privacy } \\
\hline Yes* $^{*}$ & $615(80.1)$ & & & \\
\hline No & $153(19.9)$ & .923 & .009 & $(-.170, .188)$ \\
\hline \multicolumn{5}{|c|}{ Interviewed in your language } \\
\hline Yes* & 739 (96.2) & & & \\
\hline No & $29(3.8)$ & .050 & -.356 & $(-.713, .000)$ \\
\hline \multicolumn{5}{|l|}{ Comfortable seat } \\
\hline Yes* $^{*}$ & $676(88.0)$ & & & \\
\hline No & $92(12.0)$ & .869 & -.020 & $(-.256, .216)$ \\
\hline \multicolumn{5}{|l|}{ Clean waiting area } \\
\hline Yes* $^{*}$ & 709 (92.3) & & & \\
\hline No & $59(7.7)$ & .130 & -.233 & $(-.534, .069)$ \\
\hline
\end{tabular}

*References category (categories with highest frequency taken as reference categories)

their interaction with the provider compared to those who did not know the provider at all (95\%CI: 0.129 to 0.870). Clients who did not tell their private issues had an average of 0.598 decrease in satisfaction score as compared to those who told their private issues to the provider (95\%CI: -0.761 to -0.435$)$. Moreover, patients who felt that they did not have privacy during consultation had an average decline of 0.400 in their satisfaction score as compared to those who felt there was sufficient privacy (95\%CI: $-0.570,-0.230)$.

\section{Interaction with the health care providers}

Perceived empathy was rated as good, very good or excellent by $73.3 \%$ of the respondents. Similarly, about $35 \%$ the respondents strongly disagreed/disagreed about the technical competency of the providers. Eighty two percent of the respondents rated the non-verbal communication by the provider as good, very good or excellent on the five-point Likert scale. Moreover, $52.7 \%$ and $34.1 \%$ of the respondents reported that the consultation has enabled them to be able to cope better and much 
better with life respectively. Of the total number of patients included in this study, 406 (52.9\%) and 287 (37.4\%) reported that they were told their illness and its causes, respectively. However, only 254 (33.3\%) of the respondents were given advices on how to prevent the reoccurrence of their current illness and other similar conditions in the future. More surprisingly, only 347 $(45.2 \%)$ of the patients were told to return if their symptoms get worse.

On the other hand, the present study documented that the mean duration of consultation was $6.26 \pm 2.55 \mathrm{~min}$ utes (range $=2-20$ minutes). In the light of this finding, the consultation duration was below the mean value for $447(62.1 \%)$ of the patients. However, the mean expected consultation duration was $14.02 \pm 6.73$ minutes (range $=$ 4-30). Of all the consultations considered in this study, $624(81.3 \%)$ lasted for less than the duration patients expected while 101 (13.2\%) of the consultations took more than expected. Patients over expected the consultation duration by an average of $9.92 \pm 6.33$ minutes and under expected it by an average of $2.51 \pm 2.03$ minutes.

\section{Perceived interaction with the health care provider as predictor of satisfaction}

Table 3 shows the regression estimates for the model with interaction related variables and patient satisfaction score. Accordingly, perceived empathy, perceived technical competency, non-verbal communication, patient enablement, being told the name of their illness, expectation, perceived consultation length and duration of illness were significant predictors of satisfaction. The model explained $51.8 \%$ of the variations in patient satisfaction. Respondents whose perceived poor empathy by the provider had an average drop of 0.389 in their satisfaction score as compared to the patients who perceived good empathy (95\%CI: -0.621 to -0.155$)$. Besides, as perceived empathy gets better, its effect on satisfaction score becomes more positive. Non-verbal communication had similar effect as that of perceived empathy. Respondents who rated non-verbal communication of the provider as poor have an average decrease of 0.515 unit in their satisfaction as compared to those who rated it as good (95\% CI: -0.985 to-0.046). However, patients who witnessed excellent non-verbal communication had an average increase of 0.512 unit in satisfaction score as compared to those who reported good non-verbal communication (95\%CI: 0.227 to 0.797). Moreover, Patients who disagreed to the technical competency of the providers had a satisfaction score 0.346 unit lower than those who agreed (95\%CI: -0.475 to -0.217 ).

\section{Levels of patient satisfaction with the visit}

The levels of satisfaction of the respondents with health care provider interactions are displayed in table 4 . It was found that $76(9.9 \%)$ and $405(52.7 \%)$ of the respondents were highly and moderately satisfied, respectively.

\section{Predictors of patient satisfaction with health care provider interactions}

Table 5 shows the regression estimates and the relative effect of each predictor variable for patient satisfaction with health care provider interaction. Only variables which had statistically significant association with patient satisfaction are displayed in the table. The final model explained $62.6 \%$ of the variation in patient satisfaction. As depicted in table 5, non-verbal communication, perceived empathy, perceived technical competency and the extent to which patient expectation was met were strong predictors of patient satisfaction. For instance, respondents who perceived poor empathy by the provider had an average decrease of 0.319 in their satisfaction score compared to those who perceived good empathy (95\%CI: -0558 to -0.079). For patients who perceived fair empathy by the provider, its effect on their satisfaction score was nil (unstandardized B coefficient $=0$ ). However, respondents who perceived excellent empathy has an average increase of 0.187 unit in satisfaction score as compared to patients who perceived good empathy ( $95 \% \mathrm{CI}:-0.030$ to 0.404$)$.

Perceived technical competency also has similar effects on patient satisfaction. As it moved from strongly disagree to strongly agree, the regression estimates improve from negative to positive. Moreover, respondents who were indifferent about the technical competence of the provider had an average drop of 0.285 unit in satisfaction score as compared to respondents who agreed $(95 \%$ CI: -0.467 to -0.104$)$. Similarly, patients who witnessed poor non-verbal communication had an average decrease of 0.595 unit in satisfaction score compared to those who reported good non-verbal communication (95\%CI: -1.078 to -0.112 ). However, reporting excellent non-verbal communication has an average increase of 0.560 in satisfaction score compared to good non-verbal communication (95\%CI: 0.275 to 0.846$)$.

A closer look at the explanatory variables of patient satisfaction in this study revealed that very good empathy (Beta $=-4.323)$, fair non-verbal communication $($ Beta $=-0.188)$, fewer expectation met $($ Beta $=-0.169)$ and disagreement to technical competency (Beta = -0.156) had greater negative influence on patient satisfaction. On the other hand, excellent non-verbal communication (Beta $=0.114)$ and being told the name of their illness (0.109) had pronounced positive influence on patient satisfaction.

\section{Discussion}

Empathy is crucial to the effective achievement of patient centeredness in that it encapsulates sensitivity to 
Table 3 Interpersonal interaction variables as predictors of patient satisfaction at public health centres, Central Ethiopia, January 2009

\begin{tabular}{|c|c|c|c|c|}
\hline Explanatory Variables & No. (\%) & $\mathrm{p}$-value & Unstandardized B coefficient & $95 \% \mathrm{Cl}$ for $\mathrm{B}$ \\
\hline \multicolumn{5}{|c|}{ Provider made you feel at ease ${ }^{* *}$} \\
\hline Poor & $47(6.1)$ & .001 & -.389 & $(-.621,-.156)$ \\
\hline Fair & $158(20.6)$ & & & \\
\hline Good* $^{*}$ & $277(36.1)$ & & & \\
\hline Very good & $240(31.3)$ & .000 & -.355 & $(-.511,-.199)$ \\
\hline Excellent & $46(6.0)$ & .215 & .048 & $(.002, .428)$ \\
\hline \multicolumn{5}{|c|}{ Provider examined me thoroughly** } \\
\hline Strongly disagree & $47(6.1)$ & .504 & -.079 & $(-.312, .153)$ \\
\hline Disagree & $222(28.9)$ & .000 & -.346 & $(-.475,-.217)$ \\
\hline Neither & $81(10.5)$ & .003 & -.278 & $(-.096,-.459)$ \\
\hline Agree* & $371(48.4)$ & & & \\
\hline Strongly agree & $47(6.1)$ & .000 & .424 & $(.199, .650)$ \\
\hline \multicolumn{5}{|c|}{ Provider's direct eye contact** } \\
\hline Poor & $10(1.3)$ & .032 & -.515 & $(-.985,-.046)$ \\
\hline Fair & $128(16.7)$ & .000 & -.469 & $(-.625,-.314)$ \\
\hline Good* $^{*}$ & $340(44.3)$ & & & \\
\hline Very good & $257(33.5)$ & .000 & .245 & $(.118, .372)$ \\
\hline Excellent & $33(4.2)$ & .000 & .512 & $(.227, .797)$ \\
\hline \multicolumn{5}{|l|}{ Able to cope with life ${ }^{* *}$} \\
\hline Same/less & $101(13.2)$ & .016 & -.132 & $(-.240,-.024)$ \\
\hline Better* & 405(52.7) & & & \\
\hline Much better & $262(34.1)$ & & & \\
\hline \multicolumn{5}{|c|}{ Provider told you the name of your illness } \\
\hline Yes & $406(52.9)$ & .000 & .231 & $(.107, .354)$ \\
\hline $\mathrm{No}^{*}$ & $362(47.1)$ & & & \\
\hline \multicolumn{5}{|c|}{ Provider told you to return if it gets worse } \\
\hline Yes* $^{*}$ & $486(63.3)$ & & & \\
\hline No & $282(36.7)$ & .005 & -.177 & $(-.300,-.053)$ \\
\hline \multicolumn{5}{|c|}{ Provider told cause of your illness } \\
\hline Yes & $287(37.4)$ & .922 & .006 & $(-.123, .136)$ \\
\hline $\mathrm{No}^{*}$ & $481(62.6)$ & & & \\
\hline \multicolumn{5}{|c|}{ Provider told enough about your treatment } \\
\hline Yes* $^{*}$ & $576(75.0)$ & & & \\
\hline No & $192(25.0)$ & .996 & .000 & $(-.134, .135)$ \\
\hline \multicolumn{5}{|c|}{ Provider told you ways of preventing future recurrence } \\
\hline Yes* & $516(67.2)$ & & & \\
\hline No & $252(32.8)$ & .528 & -.046 & $(-.187, .096)$ \\
\hline \multicolumn{5}{|c|}{ Match with your expectation } \\
\hline Very much* & $330(43.0)$ & & & \\
\hline Certain & $317(41.3)$ & .431 & .048 & $(-.072, .169)$ \\
\hline Only few & $106(13.7)$ & .000 & -.473 & $(-.671,-.275)$ \\
\hline Not at all & $15(2.0)$ & .003 & -.623 & $(-1.027,-.219)$ \\
\hline \multicolumn{5}{|c|}{ Duration of stay with the provider } \\
\hline Very long & $10(1.3)$ & .781 & .064 & $(-.385, .512)$ \\
\hline Long & 89 (11.6) & .149 & .123 & $(-.044, .290)$ \\
\hline Fair* & $328(42.7)$ & & & \\
\hline Short & $283(36.8)$ & .318 & .060 & $(-.058, .179)$ \\
\hline Very short & $58(7.6)$ & .001 & -.356 & $(-.571,-.141)$ \\
\hline
\end{tabular}

**Data reduction during factor analysis identified these questions to be sufficient measures of perceived empathy, perceived technical competency, non-verbal communication, and patient enablement in that order.

*References category (categories with highest frequency taken as reference categories) 
Table 4 Level of patient satisfaction with health care provider interactions at public health centres, Central Ethiopia, January 2009

\begin{tabular}{lcc}
\hline Level of satisfaction & No. & $\%$ \\
\hline Highly satisfied & 76 & 9.9 \\
Moderately satisfied & 405 & 52.7 \\
Neither satisfied nor dissatisfied & 80 & 10.4 \\
Somewhat dissatisfied & 182 & 23.7 \\
Highly dissatisfied & 25 & 3.3 \\
\hline
\end{tabular}

both the informational and emotional aspects of communication $[1,14,23,24]$. The present study found that $73.3 \%$ of the respondents rated the empathy of the health care providers as good, very good or excellent which is lower than those reported in the United Kingdom $[25,26]$. Patient enablement indicates the quality of consultation with no indication of the process going on during consultation. In this study, only $34.1 \%$ of the respondents reported that the consultation has enabled them to cope with life much better. Though this is better than the findings in the United Kingdom studies cited earlier it could possibly imply poor quality of consultation and patient enablement in the study population.

Health care providers usually feel pressured to see more patients in short time, leading to concerns. This was found to be true in this study. The mean consultation duration for the patients was 6.26 minutes whereas the mean expected consultation duration was $14.02 \pm$ 6.73 minutes. Surprisingly, $81.3 \%$ of the consultations lasted for less than the mean expected consultation duration. The consultation duration in this study is shorter than those found in previous studies [25-28]. Furthermore, health care providers have an ethical duty to teach the patients about their illness and promotion of health in every opportunity and consultation is an ample opportunity to do so [29]. However, $47.1 \%$ of the patients were not told the name of their illness. To make things worse, $62.6 \%$ of the respondents reported

Table 5 Predictors of patient satisfaction with heath care provider interactions at health centres, Central Ethiopia, January 2009

\begin{tabular}{|c|c|c|c|c|c|}
\hline Explanatory Variables & No. (\%) & p-value & Unstandardized B coefficient & Standardized B coefficient & $95 \% \mathrm{Cl}$ for $\mathrm{B}$ \\
\hline \multicolumn{6}{|l|}{ Educational status } \\
\hline Cannot read and write* & $240(31.3)$ & & & & \\
\hline Can read and write & $123(16.0)$ & .684 & -.033 & -.012 & $(-.190, .125)$ \\
\hline Grade 1-6 & $147(19.1)$ & .042 & .153 & .060 & $(.005, .300)$ \\
\hline Grade 7-12 & $207(27.0)$ & .103 & .126 & .056 & $(-.026, .278)$ \\
\hline Diploma and above & $51(6.6)$ & & & & \\
\hline \multicolumn{6}{|l|}{ Occupational status } \\
\hline Farmer* & $286(37.3)$ & & & & \\
\hline House wife & $158(20.6)$ & .007 & .198 & .080 & $(.054, .341)$ \\
\hline Student & $153(19.9)$ & .822 & .022 & .009 & $(-.169, .212)$ \\
\hline Government employment & $67(8.7)$ & .608 & -.053 & -.015 & $(-.257, .150)$ \\
\hline Merchant & $57(7.4)$ & .625 & .055 & .014 & $(-.165, .274)$ \\
\hline Others & $47(6.1)$ & .735 & .040 & .010 & $(-.194, .274)$ \\
\hline \multicolumn{6}{|c|}{ Knowing Health care provider } \\
\hline Know very well & $35(4.6)$ & .121 & .225 & .047 & $(-.059, .509)$ \\
\hline Know well & $57(7.4)$ & .095 & .189 & .050 & $(-.033, .411)$ \\
\hline Know little bit & $180(23.4)$ & .044 & .154 & .065 & $(.004, .304)$ \\
\hline Don't know at all* & $496(64.6)$ & & & & \\
\hline \multicolumn{6}{|c|}{ Frequency of visit in 12 months } \\
\hline Once ${ }^{*}$ & $563(73.3)$ & & & & \\
\hline Twice & $165(21.5)$ & .046 & -.174 & -.071 & $(-.345,-.003)$ \\
\hline Three times & $29(3.8)$ & .954 & .002 & .008 & $(-.277, .293)$ \\
\hline$\geq 4$ times & $11(1.4)$ & .025 & -.532 & -.063 & $(-.997,-.068)$ \\
\hline \multicolumn{6}{|l|}{ Type of visit } \\
\hline $\mathrm{New}^{*}$ & $683(89.9)$ & & & & \\
\hline Follow up & $85(11.1)$ & .023 & .230 & .072 & $(.031, .429)$ \\
\hline
\end{tabular}


Table 5: Predictors of patient satisfaction with heath care provider interactions at health centres, Central Ethiopia, January 2009 (Continued)

\begin{tabular}{|c|c|c|c|c|c|}
\hline \multicolumn{6}{|c|}{ Provider made you feel at ease } \\
\hline Poor & $47(6.1)$ & .009 & -.319 & -2.614 & $(-.558,-.079)$ \\
\hline Fair & $158(20.6)$ & & & & \\
\hline Good* $^{*}$ & $277(36.1)$ & & & & \\
\hline Very good & $240(31.3)$ & .000 & -.351 & -4.323 & $(-.511,-.192)$ \\
\hline Excellent & $46(6.0)$ & .091 & .187 & 1.693 & $(-.030, .404)$ \\
\hline \multicolumn{6}{|c|}{ Provider examined me thoroughly } \\
\hline Strongly disagree & $47(6.1)$ & & -.059 & -.014 & $(-.292, .173)$ \\
\hline Disagree & $222(28.9)$ & & -.343 & -.156 & $(-.476,-.211)$ \\
\hline Neither & $81(10.5)$ & & -.285 & -.088 & $(-.467,-.104)$ \\
\hline Agree $^{*}$ & $371(48.4)$ & & & & \\
\hline Strongly agree & $47(6.1)$ & & .416 & .100 & $(.191, .640)$ \\
\hline \multicolumn{6}{|c|}{ Provider's direct eye contact } \\
\hline Poor & $10(1.3)$ & .016 & -.595 & -.068 & $(-1.078,-.112)$ \\
\hline Fair & $128(16.7)$ & .000 & -.503 & -.188 & $(-.658,-.348)$ \\
\hline Good* $^{*}$ & $340(44.3)$ & & & & \\
\hline Very good & $257(33.5)$ & .001 & .224 & .106 & $(.097, .351)$ \\
\hline Excellent & $33(4.2)$ & .000 & .560 & .114 & $(.275, .846)$ \\
\hline \multicolumn{6}{|c|}{ Able to cope with life } \\
\hline Same/less & $101(13.2)$ & .014 & -.068 & -.137 & $(-.246,-.028)$ \\
\hline Better* & $405(52.7)$ & & & & \\
\hline Much better & $262(34.1)$ & & & & \\
\hline \multicolumn{6}{|c|}{ Provider told you the name of your illness } \\
\hline Yes & $406(52.9)$ & .000 & .218 & .109 & $(.106, .331)$ \\
\hline $\mathrm{No}^{*}$ & $362(47.1)$ & & & & \\
\hline \multicolumn{6}{|c|}{ Provider told you to return if it gets worse } \\
\hline Yes* $^{*}$ & $486(63.3)$ & & & & \\
\hline No & $282(36.7)$ & .000 & -.208 & -.100 & $(-.324,-.092)$ \\
\hline \multicolumn{6}{|l|}{ Expectation meet } \\
\hline Very much* & $330(43.0)$ & & & & \\
\hline Certain & $317(41.3)$ & & & & \\
\hline Only few & $106(13.7)$ & .000 & -.492 & -.170 & $(-.671,-.312)$ \\
\hline Not at all & $15(2.0)$ & .001 & -.659 & -.091 & $(-1.053,-.265)$ \\
\hline
\end{tabular}

*References category (categories with highest frequency taken as reference categories)

that the cause of their illness was not explained to them. This finding is much lower than findings in other studies carried out elsewhere [27,30,31]. Hence, there were so many missed opportunities to practice health education and promotion activities.

Non-verbal communication is a subtle form of communication that takes place in the initial three seconds after meeting someone for the first time and can continue throughout the entire interaction. It has a great impact as that of verbal communication but can be more easily misinterpreted [4]. Thus, it is important for the health care provider to be aware of the non-verbal messages they convey to their patients. In the present study, non-verbal communication significantly influenced patient satisfaction. This finding was supported by previous findings elsewhere [32,33].
Moreover, this study showed that $62.6 \%$ of the respondents were satisfied with the consultation. This finding is quite comparable with other findings in Ethiopia $[34,35]$. Finally, findings in this study indicated that perceived empathy, perceived technical competency, nonverbal communications, patient enablement and information sharing about the patient's illness were the main predictor variables of patient satisfaction with health care provider interaction. Similar findings were observed in some other studies $[32,33,36]$. However, it has to be noted that the findings of this study might suffer from response bias due to the fact that facility based studies produce more positive responses by the patient. This may result in relatively short-lived "halo effect" whereby patients feel more satisfied immediately after their consultation than they do afterwards. 


\section{Conclusion}

In conclusion, perceived technical competency, perceived empathy, non-verbal communication, being told the name of illness, frequency and type of visit, knowing the provider and patient enablement were the main predictor variables of patient satisfaction in this study. This shows that interpersonal interaction which relies on verbal and non-verbal communication is crucial in improving patient satisfaction and should be given due attention by the health care providers. Furthermore, better demonstration of empathy, information sharing about the patient's illness and greater efforts to improve patient enablement could positively affect the perception of the patients about the provider's competency and consequently their satisfaction.

\section{Acknowledgements}

We acknowledge Jimma University for funding this study. We are also grateful to the study participants for their voluntary participation.

\section{Author details}

${ }^{1}$ Jimma University, Public Health Faculty, Department of Health Education and Behavioural Sciences, Jimma, Ethiopia. ${ }^{2}$ Jimma University, Public Health Faculty, Department of Health Services Management, Jimma, Ethiopia.

\section{Authors' contributions}

ZB was involved in the conception, design, analysis, report writing and manuscript writing. TA and MW had been involved in the design, analysis and interpretation of the data, and report writing. In addition, MW was involved in manuscript review. SM assisted with the design and report writing. All authors have read and approved the final version of the manuscript.

\section{Competing interests}

The authors declare that they have no competing interests.

Received: 31 August 2009 Accepted: 24 March 2010

Published: 24 March 2010

\section{References}

1. De Geyndt W: Managing the quality of health care in developing countries. World Bank Technical Paper 1995, 258:80.

2. Girma S, et al: Human Resource Development for Health in Ethiopia: Challenges of Achieving the Millennium development Goals. Ethiop J Health Dev 2007, 21(3).

3. John Hopkins University: Defining the Patient-Physician Relationship for the 21st Century. 3rd Annual Disease Management [on the internet] 2003 [http://www.cardiophonics.com/PatientPhysician.pdf], [cited 2008 Aug 29].

4. Wisconsin A: Improving Interpersonal Communication between Healthcare Providers and Clients: Reference Manual, USA. Quality Assurance Project 1999 [http://www.qaproject.org/training/ipc/ref.pdf], [cited 2008 Nov.5].

5. Myriam D: Doctor-patient communication in general practice: An observational study in six European countries [on the internet].[http:// www.bmj.com/cgi/content/full/325/7362/472], [cited 2009 Sep 3].

6. John M, Robert R, Gilbert E: Patient-Physician Communication:Why and How. JAOA [serial on the internet] 2005, 105(1)[http://www.jaoa.org/cgi/ reprint/105/1/13.pdf], [cited 2008 Sep 16].

7. Stephen A, Summay Al, Toney R, Richard L: Patient Satisfaction with Primary Health Care Services. International Journal of Quality Health Care 2003, 15(3):241-249.

8. Bensing JM, et al: Shifts in doctor-patient communication between 1986 and 2002: a study of videotaped General Practice consultations with hypertension patients. BMC Family Practice 2006, 7:62.
9. Sharon S, Tanya A, Larry S: Patient-Centered Care for Underserved Populations: Definition and Best Practices. Washington DC: Economic and Social Research Institute 2006 [http://www.unitedwayla.org/getinformed/rr/ research/basic/Pages/Page2214.aspx], [cited on Sep3].

10. Ruby N, Heidi C, Aubrey A, Carmen R: Satisfaction with Care among LowIncome Female Outpatients. Psychology, Health \& Medicine 2007, 12(3):334-345.

11. The Federal Democratic Republic of Ethiopia: Health Sector Development Programme II. Ministry of Health, Addis Ababa 2002.

12. Andaleeb $\mathrm{S}$ : Service quality perceptions and patient satisfaction: a study of hospitals in a developing country. Soc Sci Med 2001, 52:1359-70.

13. Federal Ministry of Health: Health Policy of the Transitional Government of Ethiopia. [http://www.etharc.org/publications/moh/mohpolicy.htm], [Cited 2009 Apr 12].

14. Sudeh Ch, et al: What Patients Want From Primary Care Consultations: A Discrete Choice Experiment to Identify Patients' Priorities. Annals of Family Medicine 2007, 6:107-115[http://www.annfammed.org/cgi/content/ full/6/2/107], [cited 2008 Aug 28].

15. Theo Sc: Patient-centered Consultations: Communication Skills [monograph on the internet]. UK: The Medicine Publishing Company Ltd 2000 [http://www.asia.cmpmedica.com/cmpmedica_my/disppdf.cfm? fname=L8.pdf], [cited 2008 Sep 9].

16. Price R, Spencer J, Walker J: Does the presence of medical students affect quality in general practice consultations?: medical education. 2008, 42:374-381, [cited 2008 Sep 5].

17. Hugh M, Stewart W, Tony S, Kate J: Empathy, Enablement, and Outcome: An Exploratory Study on Acupuncture Patients' Perceptions. The Journal of Alternative and Complementary Medicine 2003, 9:869-876, [cited 2008 Oct 12].

18. Abebe B, et al: Levels of outpatient satisfaction at selected health facilities in six regions of Ethiopia. Ethiop J Health Dev 2008, 22:42-48.

19. Afework $S$, Mariam DH, Demeke B: Assessment of quality ofservices in private clinics in Addis Ababa, Ethiopia. Ethiopian Med J 2003, 41:267-78.

20. Birna A: The quality of Hospitals services in Eastern Ethiopia: Patients' perspective. Ethiopian J Health Dev 2006, 20:199-200.

21. Stewart W, David R, Graham C: The importance of empathy in the enablement of patients attending the Glasgow Homoeopathic Hospital. Br J Gen Pract 2002, 52:901-905, [cited 2008 Sep 5].

22. John C: Consultation length, patient-estimated consultation length, and satisfaction with the consultation. Br J Gen Pract 2002, 52:1004-1006, [cited 2008 Aug 28].

23. Halpern J: What is Clinical Empathy? J Gen Intern Med 2003, 18:670-674, [cited 2008 Aug 29].

24. Stewart W, Margaret M, David H, Graham C: The consultation and relational empathy (care) measure: Development and preliminary validation and reliability of an empathy-based consultation process measure. J Family Pract 2004, 21:669-705[http://fampra.oxfordjournals.org/ cgi/content/full/21/6/699], [cited 2008 Sep 15].

25. Hugh M, Stewart W, Tony S, Kate J: Empathy, Enablement, and Outcome: An Exploratory Study on Acupuncture Patients' Perceptions. The Journal of Alternative and Complementary Medicine 2003, 9:869-876, [cited 2008 Oct 12].

26. Malcolm Mc, David A: Eliciting patients concerns: a randomized controlled trial of different approaches by doctors. British Journal of General Practice 2004, 54:663-666.

27. University of Massachusetts Medical School Office of Community Programs: Physician Toolkit and Curriculum: Resources to Implement Cross-Cultural Clinical Practice Guidelines for Medicaid Practitioners. 2004 [http://www. omhrc.gov/assets/pdf/checked/toolkit.pdf], [cited on Aug 29].

28. Carol E, Carolyn T, Robin D: Assessing the patients' world: patientphysician communications about psychosocial issues. Jones and Bartlett publisher[http://www.jbpub.com/samples/0763749613/49613_CH07.pdf], [cited 2008 Oct 12].

29. Abdosh B: The quality of hospital services in eastern Ethiopia: Patient's Perspective. Ethiop J Health Dev 2006, 20:199-200.

30. Joelle $M$, Lorenz $F$, Lukas $S$, André B: Patient satisfactions of primary care for musculoskeletal diseases: A comparison between Neural Therapy and conventional medicine. BMC Complement Altern Med 2008, 8:33, [cited 2008 Sep 6]. 
31. Nancy L, Tejal K, John O, David W, John Z: Patient Characteristics and Experiences Associated With Trust in Specialist Physicians. American Medical Association 2004, 164:1015[http://archinte.ama-assn.org/cgi/reprint/ 164/9/1015], [cited 2008 Sep 14].

32. Girma A: Quality assessment of directly observed treatment short course of Tuberclosis in Afar national regional state. Ethiopian public health association. Extract No 52008.

33. Syed SA, Nazlee S, Shahjahan K: Patient satisfaction with health services in Bangladesh. Health Policy and Planning 2007, 1-11.

34. Zebiene $E$, et al: Meeting patient's expectations in primary care consultations in Lithuania. International Journal for Quality in Health Care 2004, 16:83-89.

35. McKinley RK, Stevenson, Adams S, Manku-scott TK: Meeting patient expectation of care: the major determinants of satisfaction with out of hours in primary medical care. J Family Pract Oxford University Press 2002.

36. Meg C, Fabian T, Steven R, Roger T, Rajesh B: Correlates of patient satisfaction with physician visit: Differences between elderly and nonelderly survey respondents. Health and Quality of Life Outcomes 2007, 5:62, [cited 2008 sep 23].

\section{Pre-publication history}

The pre-publication history for this paper can be accessed here: http://www. biomedcentral.com/1472-6963/10/78/prepub

\section{doi:10.1186/1472-6963-10-78}

Cite this article as: Birhanu et al.: Determinants of satisfaction with

health care provider interactions at health centres in central Ethiopia: a cross sectional study. BMC Health Services Research 2010 10:78.

\section{Submit your next manuscript to BioMed Central and take full advantage of:}

- Convenient online submission

- Thorough peer review

- No space constraints or color figure charges

- Immediate publication on acceptance

- Inclusion in PubMed, CAS, Scopus and Google Scholar

- Research which is freely available for redistribution

Submit your manuscript at www.biomedcentral.com/submit 